\title{
Modelling ozone fluxes to forests for risk assessment: status and prospects
}

\author{
Juha-Pekka TuOvINEN $^{1 *}$, Lisa EMBERSON ${ }^{2}$, David SIMPSON $^{3,4}$ \\ ${ }^{1}$ Finnish Meteorological Institute, P.O. Box 503, 00101 Helsinki, Finland \\ ${ }^{2}$ Stockholm Environment Institute, University of York, York YO10 5DD, UK \\ ${ }^{3}$ Norwegian Meteorological Institute, P.O. Box 43 Blindern, 0313 Oslo, Norway \\ ${ }^{4}$ Department of Radio and Space Science, Chalmers University of Technology, 41296 Gothenburg, Sweden
}

Keywords:

ozone /

risk assessment /

stomatal flux /

modelling /

forest monitoring

(Received 1 August 2008; accepted 30 January 2009)

\author{
Mots-clés : \\ ozone / \\ évaluation des risques / \\ flux stomatique / \\ modélisation / \\ surveillance des forêts
}

\begin{abstract}
- Risk assessment of ozone effects on forests is gradually moving from concentration-based exposure metrics to a more complicated approach that requires modelling of ozone fluxes to trees.

- This study reviews the status of the $\mathrm{DO}_{3} \mathrm{SE}$ stomatal flux model employed within the Convention on Long-range Transboundary Air Pollution, describing a range of applications and identifying major research needs, especially in the context of support that could be provided by the International Co-operative Programme on Assessment and Monitoring of Air Pollution Effects on Forests.

- The most urgent development need for $\mathrm{DO}_{3} \mathrm{SE}$ is the modelling of the soil moisture status and its effect on stomatal conductance. Furthermore, the data related to the physical characteristics and the seasonal dynamics of physiological activity of vegetation continue to pose problems.

- There is a clear need for more extensive validation of models and risk estimates using more rigorous statistical procedures and comparisons with flux networks and satellites.

- The current large-scale forest monitoring activities provide only limited possibilities for flux modelling, but could be enhanced by introducing a new monitoring strategy outlined here.
\end{abstract}

Résumé - Modélisation des flux d'ozone en forêts pour l'évaluation des risques : état et pers-
pectives. - L'évaluation des risques des effets de l'ozone sur les forêts est progressivement passée de la mesure de l'exposition à des concentrations à une approche plus complexe qui nécessite la modélisation des flux d'ozone chez les arbres.

- Cette étude passe en revue l'état du modèle de flux stomatique de $\mathrm{DO}_{3} \mathrm{SE}$ employé au sein de la Convention de la Pollution Atmosphérique Transfrontière à Longue Distance, en décrivant une série d'applications et en identifiant les principaux besoins en matière de recherche, en particulier dans le cadre de l'appui qui pourrait être fourni par le Programme Coopératif International d'Évaluation et de Surveillance des Effets de la Pollution de l'Air sur les Forêts.

- Le besoin de développement le plus urgent pour $\mathrm{DO}_{3} \mathrm{SE}$ est la modélisation de l'état d'humidité du sol et de ses effets sur la conductance stomatique. En outre, les données relatives aux caractéristiques physiques et à la dynamique saisonnière de l'activité physiologique de la végétation continuent à poser des problèmes.

- Il y a un besoin clair de validation plus large des modèles et des estimations du risque en utilisant des méthodes statistiques plus rigoureuses et des comparaisons avec les réseaux de flux et les satellites.

- Les activités courantes de surveillance forestière à grande échelle ne fournissent que des possibilités limitées de modélisation des flux, mais pourraient être améliorées par l'introduction d'une nouvelle stratégie de surveillance décrite ici.

\footnotetext{
*Corresponding author: juha-pekka.tuovinen@fmi.fi
} 


\section{INTRODUCTION}

Ozone $\left(\mathrm{O}_{3}\right)$ is a gaseous, phytotoxic secondary air pollutant that numerous experimental studies have shown to cause damage and injury to a variety of plants, including forest trees (Karnosky et al., 2007). The deleterious $\mathrm{O}_{3}$ effects on plants range from visible leaf injury to growth reduction and increased sensitivity to biotic and abiotic stress. In the troposphere, $\mathrm{O}_{3}$ is produced photochemically from volatile organic compounds (VOCs), methane and carbon monoxide in the presence of nitrogen oxides $\left(\mathrm{NO}_{\mathrm{x}}\right)$ and, with increasing emissions of these precursor compounds, tropospheric $\mathrm{O}_{3}$ concentrations have increased dramatically since pre-industrial times (Vingarzan, 2004). As a result of growing awareness of adverse $\mathrm{O}_{3}$ effects, the international actions of air pollution abatement, traditionally aimed at acidifying and euthrophying compounds, have been extended to include $\mathrm{O}_{3}$ precursor emissions $\left(\mathrm{NO}_{x}\right.$, VOC) (e.g. Grennfelt et al., 1994).

A specific feature of the European emission control strategies is that they are founded on the so-called multi-pollutant, multi-effect approach, which includes $\mathrm{O}_{3}$-induced plant injury as one of the key effects to be minimized (e.g. Maas et al., 2004). Within this framework, the risk of $\mathrm{O}_{3}$ damage to vegetation is related to numerical exposure and dose indices, which are rather uncomplicated by design, to facilitate regional-scale risk assessments, while retaining biological meaningfulness (e.g. Paoletti and Manning, 2007). The exposure- and dosetype metrics differ in that the former can be evaluated from data on ambient $\mathrm{O}_{3}$ concentrations only, while the latter involves defining the stomatal uptake of $\mathrm{O}_{3}$ by vegetation and thus, additionally, requires the stomatal conductance of plants to be measured or modelled. Both types of risk indicator are used within the air pollution assessment methodology adopted within the Convention of Long-range Transboundary Air Pollution (CRLTAP) of the United Nations Economic Commission for Europe (UNECE) (UNECE, 2004b and ongoing updates). However, there is increasing evidence for the superior biological basis of the more mechanistic dose approach (e.g. Matyssek et al., 2007).

According to the UNECE risk assessment methodology (UNECE, 2004b), the stomatal conductance required for the estimation of stomatal $\mathrm{O}_{3}$ flux and hence dose is to be calculated as a function of meteorological variables and plant phenology using a multiplicative algorithm that is based on the $\mathrm{DO}_{3} \mathrm{SE}$ (Deposition of Ozone and Stomatal Exchange) model (Emberson et al., 2000a, b, 2007a). $\mathrm{DO}_{3} \mathrm{SE}$ is incorporated into the chemical transport model (CTM) of the European Monitoring and Evaluation Programme (EMEP) (Simpson et al., 2001; 2003a; 2007), which simulates physical and chemical processes in the atmosphere, providing a link between emissions, concentrations and surface fluxes. $\mathrm{DO}_{3} \mathrm{SE}$ has been widely used in many local-scale applications, including the derivation of dose-response relationships for risk assessment (Karlsson et al., 2007; Pleijel et al., 2007), while the EMEP CTM plays a key role within the European-scale air pollution abatement strategy and legislation work (Amann and Lutz, 2000; Schneider and Schneider, 2004).
The condition of European forests is monitored within the International Co-operative Programme on Assessment and Monitoring of Air Pollution Effects on Forests (ICP Forests), which is a pan-European activity originally established under the UNECE CLRTAP and subsequently merged with a similar programme of the European Union (EU) (Fischer et al., 2007; Lorenz et al., 2008). ICP Forests runs a large-scale monitoring programme on the effects of anthropogenic and natural stress factors on forest ecosystems including over 6000 permanent observation plots across Europe to assess tree crown condition; over 800 of these are so-called intensive monitoring (Level II) plots recording a wide range of measurements of stress and response variables, including data on air quality, meteorology and phenology, for example. Thus the data provided by the ICP Forests monitoring programme could potentially contribute significantly to the development, validation and application of the modelling tools for flux-based risk assessment.

The main objective of this paper is to critically discuss the following issues related to flux modelling as applied to $\mathrm{O}_{3}$ risk assessment purposes: (1) the methods employed within UNECE, mainly the status and needs for further development of the $\mathrm{DO}_{3} \mathrm{SE}$ model; (2) possibilities and limitations of the ICP Forests monitoring programme; (3) validation and evaluation of the $\mathrm{O}_{3}$ risk assessment tools.

The paper starts with a brief summary of the UNECE flux modelling methodology (Sect. 2), defining the key concepts and indicating that both atmospheric $\mathrm{O}_{3}$ concentration and the stomatal conductance of plants must be considered. In section 3 we review the applicability of the passive sampling technique, as applied within ICP Forests, for producing the required concentration data. The main issues we discuss here are the temporal resolution of these data and the reference height of measurements, the latter also providing a framework for extending the flux model formulation to the canopy scale. Section 4 centres around the issues (1) and (2) above; we first illustrate the differences and similarities between the localand regional-scale modelling and then identify main limitations of the vegetation and meteorological data involved in flux modelling, again commenting on the potential role of ICP Forests. This section also explains briefly why non-stomatal $\mathrm{O}_{3}$ deposition and the detoxification capacity of plants must be considered in the context of stomatal $\mathrm{O}_{3}$ flux. Section 5 deals extensively with the statistical validation and robustness analysis of flux models, dose metrics and risk estimates. Here we summarise some key studies, highlighting data limitations and shortcomings in the commonly applied statistical procedures. In the final section we aim at a concise synthesis of the previous discussion and suggest an enhanced monitoring strategy that would provide a sounder basis for the flux-based risk assessment of $\mathrm{O}_{3}$ effects on forests.

\section{FLUX MODELLING PRINCIPLES}

The dose-based $\mathrm{O}_{3}$ risk indicator $\left(\mathrm{A} F_{\mathrm{st}} Y\right.$, Accumulated stomatal Flux above a threshold $Y$ ) introduced within the UNECE risk assessment methodology (UNECE, 2004b) can be 
written as

$$
\mathrm{A} F_{\mathrm{st}} Y=\sum_{i=1}^{N} \max \left(F_{\mathrm{st}, i}-Y, 0\right) \Delta t,
$$

where $F_{\text {st }}$ is the stomatal $\mathrm{O}_{3}$ flux per projected leaf area (PLA) to sunlit leaves at the canopy top and $Y$ is the threshold stomatal flux per PLA (in nmol m $\mathrm{m}^{-2} \mathrm{~s}^{-1}$ ). A $F_{\mathrm{st}} Y$ is calculated from hourly values of $F_{\mathrm{st}}$ (denoted by $i$ ), so $\Delta t=1 \mathrm{~h} ; N$ denotes the number of hours to be included in the calculation period, which corresponds to the growing season. The stomatal flux in equation (1) is defined as

$$
F_{\mathrm{st}, i}=c_{i}(h) \hat{g}_{\mathrm{st}, i}(h),
$$

where $c_{i}$ is the hourly $\mathrm{O}_{3}$ concentration, $h$ is vegetation height and $\hat{g}_{\mathrm{st}, i}$ is the hourly effective stomatal conductance (termed "effective" as the leaf boundary layer and external plant surfaces are allowed for). Thus the stomatal flux depends on two components, a concentration and a conductance, both of which are significant for flux. Correspondingly, the time-integrated stomatal flux, or $\mathrm{A} F_{\mathrm{st}} Y$ with any $Y$, depends on the covariation of these components.

It is assumed for equation (2) that $c$ is determined at a location close to the atmosphere-vegetation interface (nominally at $h$ ), so the aerodynamic resistance related to atmospheric mixing can be ignored. However, it is necessary to allow for both the quasi-laminar boundary layer enveloping the leaves and $\mathrm{O}_{3}$ deposition to the external plant surfaces. Representing the associated processes by conductances, the relationship between $\hat{g}_{\mathrm{st}}$ and the actual stomatal conductance $g_{\mathrm{st}}$ can be written as

$$
\hat{g}_{\mathrm{st}}=\frac{g_{\mathrm{b}} g_{\mathrm{st}}}{g_{\mathrm{b}}+g_{\mathrm{st}}+g_{\mathrm{ext}}}
$$

where $g_{\mathrm{b}}$ is the leaf-scale boundary layer conductance and $g_{\mathrm{ext}}$ is the leaf-scale conductance of external plant surfaces. Expressions equal to equation (3) can be presented using a combination of conductances and resistances as well (UNECE, 2004b; Simpson et al., 2007; Tuovinen et al., 2007). The boundary-layer conductance can be calculated from

$$
g_{\mathrm{b}}=\alpha L_{\mathrm{d}}^{-1 / 2} U(h)^{1 / 2},
$$

where $\alpha\left(=5.1 \times 10^{-3} \mathrm{~m} \mathrm{~s}^{-1 / 2}\right)$ is a constant, $L_{\mathrm{d}}$ is the crosswind leaf dimension and $U$ is wind speed (UNECE, 2004b; Simpson et al., 2007). A constant $g_{\mathrm{ext}}\left(=4 \times 10^{-4} \mathrm{~m} \mathrm{~s}^{-1}\right)$ is assumed in $\mathrm{DO}_{3} \mathrm{SE}$.

In $\mathrm{DO}_{3} \mathrm{SE}, g_{\mathrm{st}}$ is modelled using a multiplicative plant species-specific parameterisation representing the stomatal responses to environmental and phenological factors (Emberson et al., 2000a; UNECE, 2004b). There are alternative formulations of $\mathrm{DO}_{3} \mathrm{SE}$, but the basic form can be written as

$$
g_{\mathrm{st}}=g_{\max } f_{1}(t) f_{2}\left(I_{\mathrm{p}}\right) \max \left[f_{3}(T) f_{4}\left(D_{\mathrm{e}}\right) f_{5}(\Psi), f_{\min }\right],
$$

where $g_{\max }$ is the maximum stomatal conductance, which is reduced by the functions $f_{1}, f_{2}, \ldots, f_{5} \in[0,1]$ depending on time of year $t$ (phenology), photosynthetic photon flux density $I_{\mathrm{p}}$, air temperature $T$, atmospheric water vapour pressure deficit (VPD) $D_{\mathrm{e}}$ and soil water potential (SWP) $\Psi$, respectively; $f_{\min }>0$ is a minimum value introduced to ensure a non-zero value for the environmental response (i.e. $f_{2} f_{3} f_{4} f_{5}$ ) during the daytime (at night $f_{2}(0)=0$ ).

\section{MEASURING CONCENTRATION}

\subsection{Passive sampling alternative}

As indicated by equations (1) and (2), the stomatal flux for $\mathrm{A} F_{\mathrm{st}} Y$ is, by definition, to be calculated from hourly-averaged $\mathrm{O}_{3}$ concentration data. These data could be obtained from a standard $\mathrm{O}_{3}$ analyzer that is based on UV absorption photometry; this is the reference method defined in the EU Directive on ambient ozone (EU, 2002) and recommended for use within EMEP (EMEP, 1995). Within the ICP Forests programme, passive sampling is defined as an option for concentration measurements (UNECE, 2000) and, being relatively inexpensive and easy to deploy in the field, is widely used at the ICP Forests Level II monitoring plots across Europe (Fischer et al., 2007). Sanz et al. (2007) demonstrated the feasibility of this method for regional mapping of average $\mathrm{O}_{3}$ concentrations. However, a comparison against the reference method at some ICP Forests sites revealed the methodological uncertainty related to passive sampling. As compared to the co-located continuous analyzers calibrated on a regular basis, the coefficient of determination $\left(r^{2}\right)$ of the linear regression between the methods varied within 0.09-0.97 (annual data of weekly or biweekly averages over 6 or 12 months) (Sanz et al., 2007).

A fundamental property of passive sampling is the timeaveraging of the measurement. As a typical sampling time for $\mathrm{O}_{3}$ is two weeks (UNECE, 2000), the concentration data obtained have a low temporal resolution as compared to the definition of many air quality indicators (e.g. Paoletti et al., 2007); this is especially so for $\mathrm{A} F_{\mathrm{st}} Y$. Thus hourly data must be derived from the measured mean (14-d or so) concentration using a statistical technique with some auxiliary data; methods based on meteorological (Krupa et al., 2003) and topographical (Loibl et al., 1994) data have been suggested. This requires a significant amount of prior (hourly) calibration data, and unavoidably further uncertainty is introduced in the modelled hourly values, as exemplified by the results of Gerosa et al. (2007), who compared the modelled AOT40 (Accumulated exposure Over a Treshold of $40 \mathrm{ppb}$ ) values against measurements at 37 monitoring sites in south-west Europe and found differences of up 77\% (median 16\%). Moreover, it is questionable to what extent the correlation between high $\mathrm{O}_{3}$ concentrations and environmental factors limiting stomatal uptake, which was a major motivation for the flux-based approach in the first place (Fuhrer et al., 1997), can be simulated by this approach. The methodological and averaging problems outlined above would be avoided, if it were possible to employ the reference measurement method providing hourly data, as required for flux modelling. 


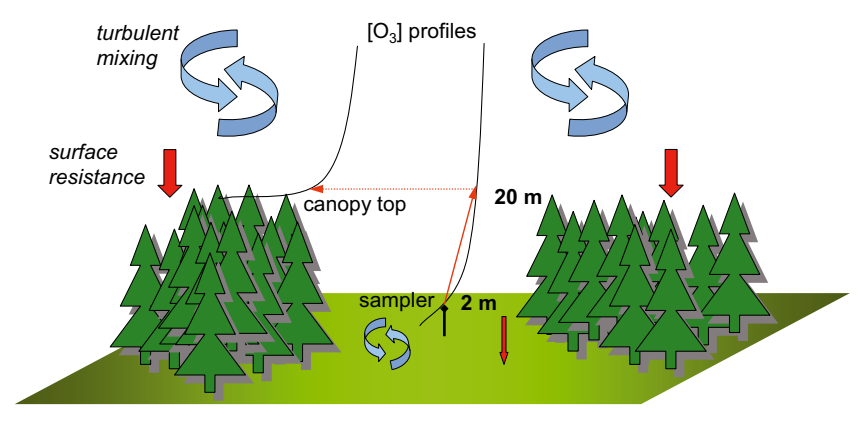

Figure 1. Schematic presentation of the height transformation required for estimating the canopy-top concentration from an openfield measurement. The measured concentration $\left(\mathrm{O}_{3}\right)$ is transformed to the canopy-top height (continuous arrow) according to the openfield conditions (turbulent mixing, total surface resistance). The transformed concentration is assumed to approximate the canopy-top concentration (dotted arrow).

\subsection{Reference height}

According to the monitoring recommendations of ICP Forests, the passive samplers are to be located in an open field near, but outside, the forest at a 2-4-m height (UNECE, 2000). This mimics the typical inlet height for continuous analyzers within a common monitoring station set-up (EMEP, 1995). This height contrasts with the definition of stomatal flux (Eq. (2)), which should be calculated using the canopytop concentration (for forest trees at $h \sim 20 \mathrm{~m}$ ). Consequently, the measured concentration must be transformed to the correct reference height (Fig. 1). This can be accomplished by using a flux-gradient model that relates the vertical concentration profile to the properties of the atmospheric flow (wind speed, stability) and the underlying surface (aerodynamic roughness, resistance of $\mathrm{O}_{3}$ deposition) by assuming that the vertical flux densities remain approximately constant within the atmospheric surface layer (e.g. Tuovinen, 2000). Based on this model, the canopy-top concentration can be calculated from

$$
c(h)=\frac{V_{\mathrm{d}}\left(z_{\mathrm{m}}\right) c\left(z_{\mathrm{m}}\right)}{V_{\mathrm{d}}(h)},
$$

where $V_{\mathrm{d}}$ is deposition velocity and $z_{\mathrm{m}}$ is the concentration measurement height. $V_{\mathrm{d}}$ is commonly expressed in terms of transfer resistances as

$$
V_{\mathrm{d}}(z)=\left[R_{\mathrm{a}}\left(z_{0}+d, z\right)+R_{\mathrm{b}}+R_{\mathrm{s}}\right]^{-1},
$$

where $z$ is height above ground level, $R_{\mathrm{a}}\left(z_{1}, z_{2}\right)$ denotes the aerodynamic resistance between the heights $z_{1}$ and $z_{2}, z_{0}$ is the roughness length of momentum, $d$ is zero-plane displacement, $R_{\mathrm{b}}$ is the canopy-scale quasi-laminar boundary-layer resistance and $R_{\mathrm{S}}$ is the canopy-scale surface resistance. $R_{\mathrm{S}}$ combines both stomatal and non-stomatal deposition pathways, which can be assumed to operate in parallel and expressed in terms of the corresponding conductances:

$$
R_{\mathrm{s}}=\left(G_{\mathrm{st}}+G_{\mathrm{nst}}\right)^{-1},
$$

where $G_{\text {st }}$ is the canopy-scale stomatal conductance, obtained by up-scaling the leaf-scale $g_{\text {st }}$ (Eq. (5)), and $G_{\text {nst }}$ is the total non-stomatal conductance corresponding to the up-scaled $g_{\text {ext }}$ and other non-stomatal sinks.

In principle, this kind of model is founded on the micrometeorological Monin-Obukhov similarity theory (MOST) which assumes, among other things, horizontal homogeneity of the underlying surface (Garratt, 1992). Due to the forest edges, the homogeneity assumption is not fulfilled very accurately within the experimental configuration scrutinised here. Furthermore, neutral atmospheric stability, constant $R_{\mathrm{s}}$ and independence of $c(h)$ of the underlying vegetation were employed as necessary assumptions by Schaub et al. (2007), who modelled $\mathrm{O}_{3}$ doses using monitoring data from ICP Forests sites. This study aimed to examine whether these provide an adequate basis, in terms of data availability and quality, for modelling stomatal $\mathrm{O}_{3}$ fluxes and doses, and indeed was successful in that. However, the implications of the various assumptions adopted for the calculation procedure were not considered. Obviously, a more representative measurement height for $\mathrm{O}_{3}$ concentration would amend the situation fundamentally and obviate such considerations.

If the $\mathrm{O}_{3}$ concentration is measured above the canopy top, a corresponding profile correction, here reducing the concentration, is necessary as well. In this case, the correction is complicated by the presence of the so-called roughness sublayer (RSL), which affects the flux-gradient relationships above aerodynamically rough surfaces such as forest canopies (Garratt, 1992). Correction methods exist for the RSL effects but these must be perceived as semi-empirical, as compared to the more fundamental MOST. The need for a RSL correction is not limited to measurement data but also applies to CTMs in which the near-surface gradients are not explicitly resolved. Tuovinen and Simpson (2008) presented a practical calculation method for the problem and concluded that the RSL can significantly affect the canopy-top concentrations and associated exposure and dose indices. However, the effect is smaller for forests than crops.

\section{MODELLING STOMATAL FLUX}

\subsection{Local- vs. regional-scale applications}

There are large differences in the seasonal and diurnal $\mathrm{O}_{3}$ dose experienced by European forest tree species, not only because of the spatial and temporal variations in $\mathrm{O}_{3}$ concentration but also because of the biological variability in uptake capacity. The latter is related to the diversity of forest species and within-species variation, which vary with geographical location and climatic features across Europe. This diversity will manifest itself in traits of phenology (timing and duration of growing seasons), physiology (e.g. stomatal response to environmental variables) and structure (e.g. canopy height, leaf area index (LAI), leaf/needle size).

All these factors may influence $\mathrm{O}_{3}$ uptake and ideally would be incorporated in the modelling of stomatal $\mathrm{O}_{3}$ flux to ensure 
that risk assessments are representative of local conditions across the continent. In practice, the $\mathrm{DO}_{3} \mathrm{SE}$ model has to be configured in a pragmatic way, with three major types of application:

(1) Local-scale or species-specific parameterisations have been defined for the $\mathrm{DO}_{3}$ SE model by UNECE (2004b), intended primarily for use for national-scale risk assessments, where site-specific data are more readily available. As defaults, UNECE (2004b) defined climatically representative tree species for four large regions (e.g. Continental Central Europe) based upon known sensitivity to $\mathrm{O}_{3}$, economic and ecological importance, and inclusion of both evergreen and deciduous forests.

(2) For the regional-scale studies conducted with the EMEP CTM, the deposition module built upon $\mathrm{DO}_{3} \mathrm{SE}$ (EMEP$\mathrm{DO}_{3} \mathrm{SE}$ ) has been parameterised for 16 land cover classes (LCCs) representing the most common surface types occurring in Europe (Emberson et al., 2000a; Simpson et al., 2003a). Four forest LCCs are defined, with data for representative species used for each class. For example, the parameterisation for temperate/boreal coniferous forests is based upon data on Norway spruce and Scots pine, and that of temperate/boreal deciduous forests on oaks, beech and birches (Emberson et al., 2000a).

(3) For regional-scale integrated assessment modelling (IAM) within UNECE and the EU, results from the EMEP CTM are typically combined with emission control options and pollutant effects, providing information for framing costeffective and effects-founded international pollution abatement policies (Schöpp et al., 1999; Maas et al., 2004). IAM cannot cope with many different risk indicators, and in an effort to capture vegetation effects without being too speciesspecific, UNECE (2004b) devised so-called generic parameterisations for $\mathrm{DO}_{3} \mathrm{SE}$. These include the "generic" deciduous forest (with characteristics based largely upon beech data) and the "generic" Mediterranean evergreen forest (based largely upon Holm oak). Furthermore, the stomatal model is significantly simplified by assuming no soil moisture limitations $\left(f_{5}(\Psi)=1\right.$ in Eq. (5)), resulting in "worst-case" risk scenarios (Simpson et al., 2007).

Figure 2 provides an overview of how the different parameterisation approaches and spatial scales are interrelated within the work carried out under the auspices of the UNECE CLRTAP.

In addition to the different parameter values, an important choice is between the leaf-scale stomatal flux to the sunlit leaves of upper canopy (i.e. flux per leaf area), as detailed in Section 2, and the total flux to the whole canopy. Work aimed at estimating $\mathrm{A}_{\mathrm{st}} Y$ for $\mathrm{O}_{3}$ effects (e.g. local-scale studies or IAM work) generally focusses on the leaf-scale, whereas CTM studies aimed at modelling atmospheric chemistry must quantify losses to the whole canopy since these determine the transport time-scale of $\mathrm{O}_{3}$. However, canopy-scale modelling may be necessary even within local-scale assessments with measured concentration data (using Eq. (2)), if a profile correction is needed for the measurement height of concentration (Sect. 3.2), or if the whole-tree $\mathrm{O}_{3}$ uptake is to be estimated.

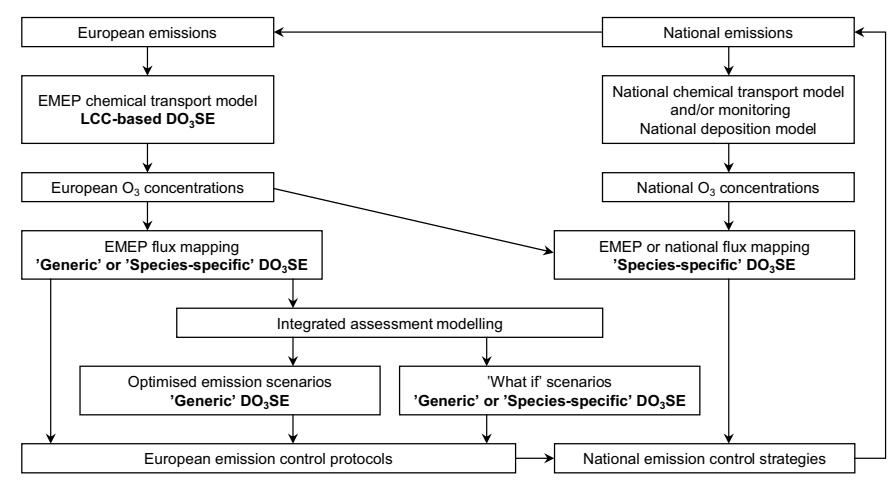

Figure 2. Role of the different $\mathrm{DO}_{3} \mathrm{SE}$ parameterisations within the European air pollution abatement strategy work.

Within the EMEP CTM, the necessary up-scaling between $g_{\text {st }}$ (Eq. (5)) and $G_{\text {st }}$ (in Eq. (8)) is obtained as a function of LAI and the within-canopy irradiance, calculated according to a canopy light extinction model which distinguishes sun and shade leaves (Emberson et al., 2000a). In principle, more detailed methods for within-canopy variation in radiation and leaf morphology should be used, for example to account for the fact that shade leaves have a lower $g_{\text {st }}$ that saturates at higher light levels (e.g. Nunn et al., 2005). Accounting for these and other factors such as temperature profile is relatively simple in terms of model formulations (e.g. Meyers and Baldocchi, 1988; Zhang et al., 2001; Juang et al., 2008); but the real problem lies in the parameterisation of such model components. For example, the fraction of sun and shade leaves present within the canopy is likely to be heavily dependent upon species, environmental conditions and LAI (Schulze et al., 1977).

\subsection{Vegetation data}

Phenology is a primary driver of the seasonality of fluxes. The most important phenological periods to define for forests trees are the start and end of the physiologically active growth period (SGS and EGS, respectively). Within $\mathrm{DO}_{3} \mathrm{SE}, \mathrm{SGS}$ and EGS are assumed to depend on the latitude, with some refinements for the species-specific parameterisation (UNECE, 2004b). This was deemed more robust for use across Europe than alternative methods that assess, for example, leaf budburst and the onset of dormancy according to effective temperature sums and/or chilling days and photoperiod (e.g. Chuine, 2000).

Although it is often recommended that simple temperaturebased methods can be used to define growing seasons, comparisons with real data have revealed weaknesses in most suggestions. As an example, Figure 3 compares a number of suggested methods to estimate SGS against carbon dioxide $\left(\mathrm{CO}_{2}\right)$ flux observations from the CarboEurope network (e.g. Reichstein et al., 2007). This figure also shows results from the $\mathrm{DO}_{3} \mathrm{SE}$ model, here run in a mode in which the usual explicit phenology-dependence is ignored, so the $g_{\mathrm{st}}$ changes are driven entirely by $I_{\mathrm{p}}, T$ and $D_{\mathrm{e}}$. The results show that the 

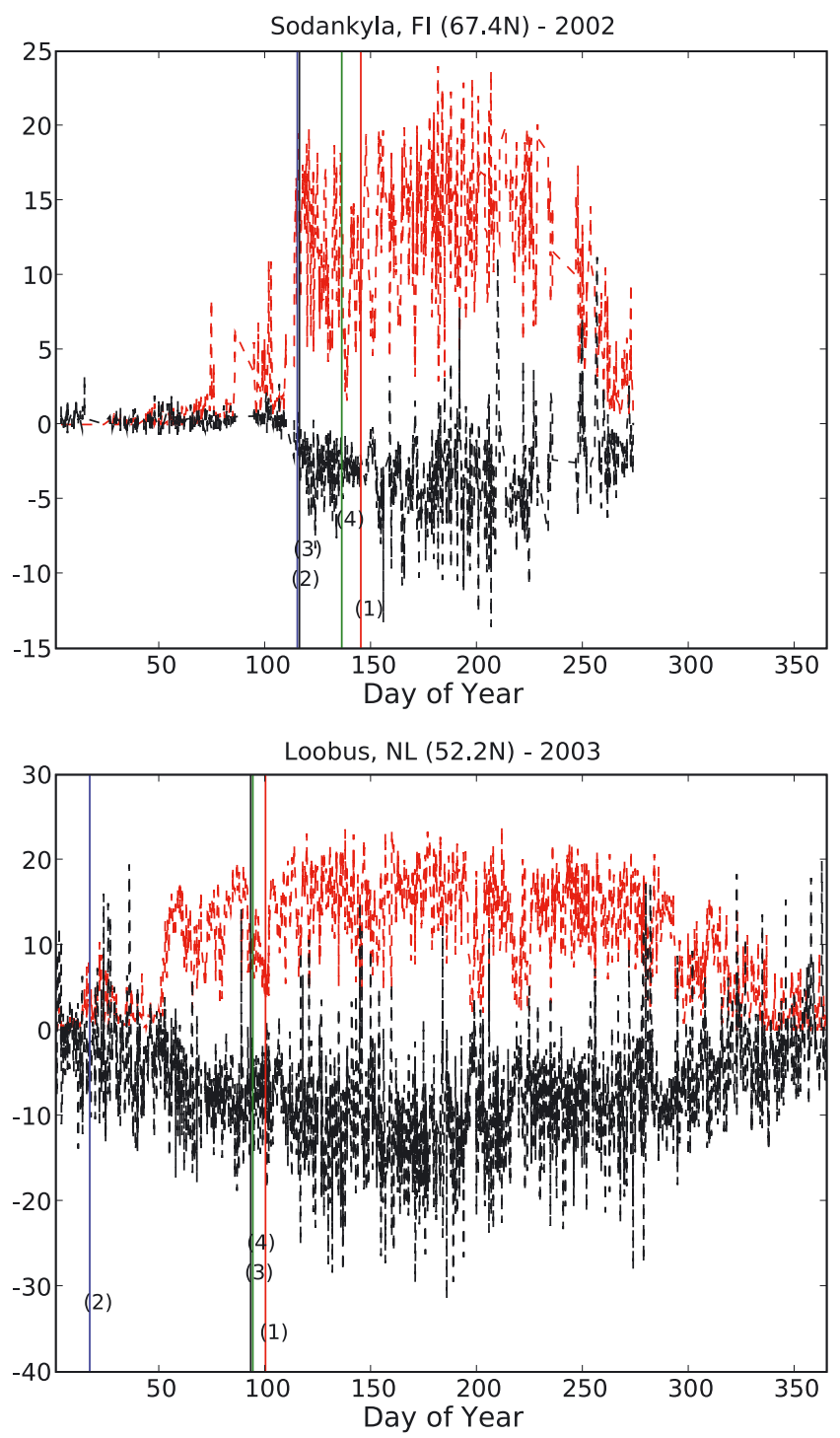

Figure 3. Estimation of the growing season start (SGS) for two sites from the CarboEurope network, Sodankylä, Finland (top) and Loobos, Netherlands (bottom). The upper curve illustrates $\mathrm{CO}_{2}$ fluxes observed above a Scots pine forest, while the lower one shows calculated stomatal conductances from the $\mathrm{DO}_{3} \mathrm{SE}$ model, when driven by temperature, irradiance and humidity only (i.e. no explicit phenological factor) (both in arbitrary units). The vertical lines illustrate the estimated SGS from four methods: (1) day when the mean 24-h temperature $\left(T_{24}\right)$ remains "permanently" (before midsummer) above $5{ }^{\circ} \mathrm{C}$; (2) first day when $T_{24}$ exceeds $5{ }^{\circ} \mathrm{C}$ for 5 consequtive days; (3) the default EMEP latitude model, SGS $=105+1.5(\varphi-60)$, where $\varphi$ is latitude; (4) the latitude-height function of Morén and Perttu (1994).

SGS estimates can differ by 1-2 months. For the Dutch site, Method 2 (5-day mean $T$ above $5{ }^{\circ} \mathrm{C}$ ) would seem to offer the most reliable indicator of SGS, but in other cases Method 3 (the default latitude-dependent model) performed just as well or better (one example shown here). It is also clear that running $\mathrm{DO}_{3} \mathrm{SE}$ without the phenology assumptions reproduces the seasonal variation in biological activity reasonably well, implying that $I_{\mathrm{p}}$ and $T$ responses of the stomatal model alone may be sufficient to determine SGS.

The opportunities afforded by remotely sensed data to identify SGS and EGS should be investigated, especially now that reliable methods to derive the Fraction of Absorbed Photosynthetically Active Radiation (FAPAR) from data acquired by a variety of Earth observing instruments have been developed (Verstraete et al., 2008). Whereas the Normalized Difference Vegetation Index can only detect the onset of greenness (Zhang et al., 2006), FAPAR is especially relevant since it is directly related to vegetation growth and development. However, such methods are still unable to provide information on the variation in phenology between species occurring in close proximity; as such the collation of ground-observed data describing the sequence in which species SGS and EGS occurs would be important.

Leaf area index, upon which the absolute scaling from leaf to canopy depends, has long been recognised as an important, yet frustratingly difficult variable to parameterise. In EMEP-DO ${ }_{3} \mathrm{SE}, \mathrm{LAI}$ is parameterised for each LCC by defining its maximum and minimum values and a simplified seasonal development determined by SGS and EGS (Simpson et al., 2003a), with some further details added for the speciesspecific version (UNECE, 2004b). In reality, LAI varies considerably across Europe with species, climate, stand age and local site conditions, all affecting the maximum values at any location. The LAI of mature Norway spruce trees, for example, is known to vary from less than $3\left(\mathrm{~m}^{2} \mathrm{~m}^{-2} \mathrm{PLA}\right)$ in northern boreal forests (Hatakka et al., 2003) to over 12 (Nilson et al., 1999), but we are not aware of any LAI map that captures this variation. Although remotely sensed data should in theory offer the opportunity to define the European-scale variation in LAI, in practice the use of such data is limited since the algorithms tend to saturate at quite low LAI values (generally for LAI > 3; Braswell et al., 1996), and most global vegetation maps tend to have very low LAI values over Europe, typically below 4-5 (e.g. Tian et al., 2004). Additionally, for forests, an understanding of stand-scale as well as individual tree LAI would ideally be provided to account for the influence of stand density on stomatal $\mathrm{O}_{3}$ flux per unit ground area.

The ICP Forests monitoring programme could potentially produce valuable information to help improve the canopyscale modelling of flux simply by providing standardised, species-specific data describing seasonal observations of LAI along with the sun-to-shade leaf morphology canopy fractions. Such observations could be conducted at Level II sites selected so as to ensure a broad range of species and environmental conditions are represented. Moreover, a more extensive collation of phenological data across Europe would help to evaluate alternative growing-season models and provide an indication of the inter-annual variation.

\subsection{Meteorological data}

The modelling of stomatal conductance with $\mathrm{DO}_{3} \mathrm{SE}$ requires data on wind speed (Eq. (4)) and other meteorological variables to derive the environmental controls indicated 
in equation (5). Within the ICP Forest programme, the recommended height for wind measurements is $10 \mathrm{~m}$, while for most of the other meteorological variables it is $2 \mathrm{~m}$ (UNECE, 2004), which are in agreement with the recommendations of the World Meteorological Organization (WMO, 1996). However, for modelling the data should represent conditions at the canopy top, which means that the measured wind, temperature and humidity data should be transformed to this height, using a micrometeorological flux-gradient relationship similar to that employed for the vertical concentration profile (Sect. 3.2). In addition, if the soil moisture status is not measured, as is the case at the ICP Forests monitoring plots, soil moisture deficit (SMD) needs to be modelled based on water budget principles when applying the $\mathrm{DO}_{3} \mathrm{SE}$ model (Ashmore et al., 2007; Emberson et al., 2007a; Schaub et al., 2007).

The determination of SMD and the related stomatal response function has proved challenging in the context of $\mathrm{O}_{3}$ flux modelling (Emberson et al., 2007a). Under drought conditions, which have a tendency to co-occur with high $\mathrm{O}_{3}$ concentrations (e.g. Solberg et al., 2008), soil water stress results in closure of the stomata as trees attempt to limit water loss; this may reduce stomatal $\mathrm{O}_{3}$ uptake dramatically (e.g. Nunn et al., 2005; Gerosa et al., 2009). The data required for estimating SMD range from those which are often readily available (precipitation, temperature), to data which are typically recorded only at selected research sites, including descriptions of soil characteristics, root distributions and measurements of water fluxes. For large-scale assessments, estimation of such data poses major problems.

Although soil maps are available at quite fine resolution on even global scales, the quality of such maps is very variable and difficult to evaluate. For example, the ISRIC-WISE database (Batjes, 2006) is believed to be one of the most complete and detailed sources of data on soils and soil-profiles, but Batjes (2006) recognised that data quality of the underlying sources ranges from good to poor, with incomplete datasets and incompatible methodologies applied in different countries. Such difficulties are not surprising, as soil characteristics can vary markedly on small scales, and soil surveys can only sample a tiny fraction of the globe's surface. Further, any regionalscale application of $\mathrm{DO}_{3} \mathrm{SE}$ must use grid sizes which encompass a large number of different soil types, with no simple way to either know or aggregate their properties. The data on the rooting depths of trees is similarly limited, but would be important for correctly modelling the extractable soil water, especially in the Mediterranean region (Emberson et al., 2007a).

A further problem for both local- and large-scale estimates is that $g_{\mathrm{st}}$ is thought to be driven by SWP rather than SMD. The relationship between these two variables is both non-linear and sensitive to assumptions on soil characteristics (e.g. Jones, 1992), and even moderate uncertainties in SMD can lead to very large (orders of magnitude) uncertainties in SWP. As a result of such difficulties, a method to estimate soil water stress and its influence on $g_{\mathrm{st}}$ has not, as yet, been agreed upon for EMEP or UNECE mapping purposes. However, it is clear that the influence of soil water status on stomatal $\mathrm{O}_{3}$ flux needs to be considered in both local- and large-scale risk assessments, and especially for the Mediterranean region where soil wa- ter deficits are the norm rather than the exception. During dry summers, which may become more frequent in the future, severe drought may be experienced across the continent (Granier et al., 2007). Thus further development of methods needs to be prioritised as a matter of some urgency to ensure that fluxbased risk assessments can be performed reliably at the European scale.

One of the key issues for developing and evaluating the SMD parameterisations is access to high-quality data describing soil or leaf water variables (e.g. pre-dawn leaf water potential, volumetric soil water content), with associated meteorological data, over an entire year. Targeted forest monitoring activities could provide an excellent opportunity for measurements of these variables to be made according to a standardised protocol across the whole of Europe for a range of species under varying soil and precipitation conditions. In addition, data from current flux networks may help to elucidate the relationship between soil water balance and latent heat fluxes.

\subsection{Role of non-stomatal deposition}

As equations (3) and (8) indicate, there is a non-stomatal deposition component parallel to the stomatal one, which must be taken into account in both leaf- and canopy-scale modelling. The mechanisms behind this deposition pathway are not fully understood, but it has been commonly observed, both on leaf and canopy scales, that the total $\mathrm{O}_{3}$ deposition flux exceeds the stomatal $\mathrm{O}_{3}$ flux estimated on the basis of water vapour exchange (e.g. Cieslik, 2004; Altimir et al., 2006). Possible non-stomatal removal mechanisms include temperature- or irradiance-induced chemical reactions on or near plant and soil surfaces (Cape et al., 2009), and in-canopy reactions with biogenic emissions of nitric oxide and numerous VOCs (Kurpius and Goldstein, 2003). Surface wetness has also been observed to significantly modify, in most cases increase, non-stomatal deposition rates (Altimir et al., 2006; Massman, 2004).

Non-stomatal deposition is significant not only to the total $\mathrm{O}_{3}$ removal rate, but also to the partitioning of the flux between its stomatal and non-stomatal components. If the concentration is measured above the vegetation canopy, the calculation of the canopy-top concentration depends on the bulk nonstomatal conductance (Eqs. (6)-(8)), which should cover all the sinks (soil, external plant surfaces, in-canopy chemistry). In the deposition models, these can be represented by individual resistance/conductance terms. In the EMEP-DO ${ }_{3} \mathrm{SE}$ module, the canopy-scale $G_{\text {nst }}$ is obtained by scaling the leaf-scale $g_{\text {ext }}$ (Sect. 2) by LAI and adding an effective soil resistance that depends on the intensity of in-canopy mixing (Emberson et al., 2000a; Simpson et al., 2003b).

Figure 4 shows how $\mathrm{A} F_{\text {st }} Y$ responds to the conductance of external plant surfaces, as calculated using the $\mathrm{DO}_{3} \mathrm{SE}$ model and data from the EMEP CTM. The data used for these calculations represent the "generic" deciduous forest LCC (Sect. 4.1) in a German grid element (Tuovinen et al., 2007). The results are presented for different threshold values, with $Y=0$ corresponding to the total dose, $Y=1.6$ 


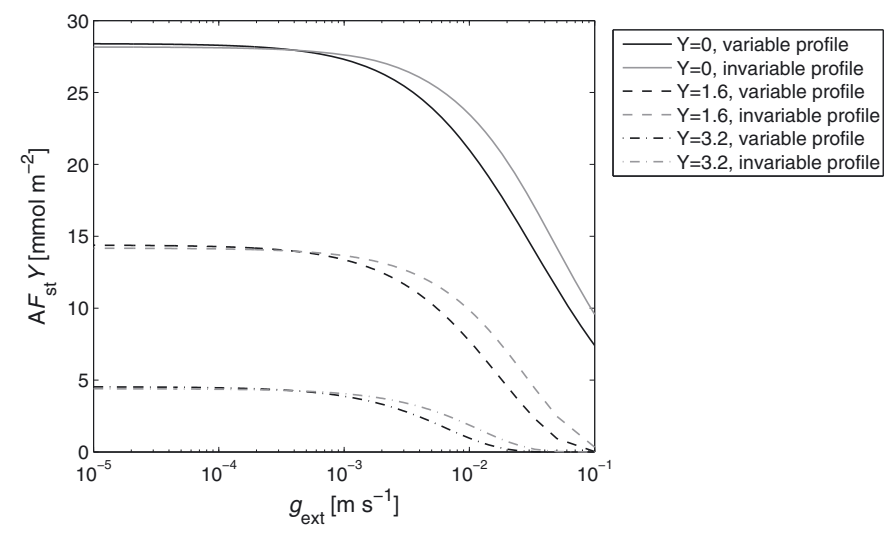

Figure 4. Dose index $\mathrm{A} F_{\mathrm{st}} Y$ as a function of the external plant surface conductance for different values of $Y$ (in mmol m $\mathrm{m}^{-2} \mathrm{~s}^{-1}$ ). For "variable profile" the canopy-top concentration is altered according to the change in $g_{\text {ext }}$ from the default $\mathrm{DO}_{3} \mathrm{SE}$ value, while for "invariable profile" the profile corresponds to this default value.

$\left(\mathrm{mmol} \mathrm{m} \mathrm{m}^{-2} \mathrm{~s}^{-1}\right)$ being the value used for the current critical level for forests (UNECE, 2004b) and $Y=3.2$ illustrating the sensitivity of $\mathrm{A} F_{\mathrm{st}} Y$ to $Y$. The modelled $\mathrm{A} F_{\mathrm{st}} Y$ is rather insensitive to $g_{\text {ext }}$, if $g_{\text {ext }}<10^{-3} \mathrm{~m} \mathrm{~s}^{-1}$ (Fig. 4). The current $g_{\text {ext }}$ value of $\mathrm{DO}_{3} \mathrm{SE}\left(4 \times 10^{-4} \mathrm{~m} \mathrm{~s}^{-1}\right)$ lies within this region. For higher values, $\mathrm{A} F_{\mathrm{st}} Y$ becomes increasingly sensitive to $g_{\mathrm{ext}}$, indicating the growing importance of non-stomatal deposition.

As mentioned above, the surface removal of $\mathrm{O}_{3}$ by any mechanism affects the vertical concentration profile and hence $c(h)$ and $F_{\text {st }}$. This effect is also demonstrated in Figure 4, which shows how the calculated $\mathrm{A} F_{\mathrm{st}} Y$ is altered when modifying the calculated vertical profile according to the change in $g_{\text {ext }}$. In this example, the modelled $\mathrm{O}_{3}$ concentration at the lowest grid level of the EMEP model, at approximately $z=45 \mathrm{~m}$, is assumed to be independent of the local deposition rates, and $c(h)$ is calculated from it with equation (6) (Tuovinen et al., 2007).

\subsection{Role of detoxification}

Flux modelling aims at quantifying the $\mathrm{O}_{3}$ dose absorbed by vegetation. In terms of plant physiology, $\mathrm{O}_{3}$ dose is a more mechanistic-based concept than $\mathrm{O}_{3}$ exposure that is insensitive to variations in stomatal conductance, which ultimately controls the gas exchange. However, the absorbed dose is not the sole determinant of plant response, as the antioxidative or detoxification capacity of plants may play an important role (e.g. Matyssek et al., 2007; 2008). Thus it is appropriate to differentiate between the "dose" and "effective dose" concepts, the latter of which allows for the plant defence mechanisms (Musselman et al., 2006). These mechanisms are intensively studied and have been shown to be dynamic but have proven difficult to quantify (Matyssek et al., 2008). Thus no models suitable for risk assessment purposes exist yet, but conceptual models have been suggested that relate plant defence to the rate of photosynthesis, illustrating the dynamics of the differ- ent components contributing to effective dose (Massman et al., 2000; Massman, 2004).

As the detoxification capacity of trees may be particularly low at night (Musselman and Minnick, 2000), the assumption that the stomata are shut in the night-time, thus preventing any $\mathrm{O}_{3}$ uptake during this period, becomes critical for the effective dose in particular. A number of studies have shown that for some species there is significant conductance during the nighttime (e.g. Körner, 1994; Matyssek et al., 1995; Musselman and Minnick, 2000; Grulke et al., 2004). This may have significant implications for risk assessment and necessitate a reconsideration of the $\mathrm{DO}_{3} \mathrm{SE}$ model, in which the light-response function will block any nocturnal uptake (in Eq. (5) $f_{2}\left(I_{\mathrm{p}}\right)=0$, if $I_{\mathrm{p}}=0$ ). However, this would require an assessment of the extent of this night-time flux, both in terms of species and geographical distribution. In addition, there is evidence of variation in detoxification capacity with age-dependent changes in leaf/needle morphology (e.g. Wieser et al., 2002). Developing the capability to distinguish fluxes to these different component canopy fractions may be important to understand responses to $\mathrm{O}_{3}$ uptake.

It should be noted that, in spite of the criticism by Musselman et al. (2006), in principle $\mathrm{A} F_{\text {st }} Y$ can be considered a metric for the effective dose, as the threshold $Y$ can be viewed as acting as a crude surrogate for the detoxification capacity. Within the UNECE methodology, the value of $Y$ was maintained at $1.6 \mathrm{mmol} \mathrm{m} \mathrm{m}^{-2} \mathrm{~s}^{-1}$ in view of the lack of new data to warrant a change from the value established for regional-scale forest risk assessments, which was based on the data collated and analysed by Karlsson et al. (2007). Even though the defence mechanisms vary diurnally and seasonally in reality, a non-zero $Y$ still provides an estimate for this variation, even if the simplest possible one. Obviously, with improving mechanistic understanding the magnitude as well as constancy of the detoxification parameter will be due for review, with an emphasis on leaf morphology, phenology and environmental conditions (Tausz et al., 2007; Matyssek et al., 2008). Here it may also be necessary to introduce further interactive elements such as the negative feedback effect on plant defence resulting from $\mathrm{O}_{3}$ uptake (Massman, 2004).

\section{MODEL VALIDATION AND ANALYSIS}

\subsection{Validation of fluxes and $\mathrm{DO}_{3} \mathrm{SE}$}

The performance of a CTM is generally assessed by comparing the modelled concentrations against a large set of observations, as is done with the EMEP model on a routine basis (e.g. Jonson et al., 2006; Simpson and Hjellbrekke, 2008). For $\mathrm{O}_{3}$ deposition fluxes, opportunities for the same are much more limited, due to a small number of flux measurement sites and the more complicated nature of these measurements. Even though a direct comparison of modelled and observed fluxes, expressed as the total annual or seasonal deposition (as for acidifying compounds), would be a useful exercise for demonstrating the performance of a CTM, the deposition flux is not 
the optimal variable for validating deposition parameterisations with site-specific data. This is because the measured $\mathrm{O}_{3}$ concentration must be used for deriving the model-based flux (cf. Eq. (2)), which will artificially increase the correlation of fluxes as concentration typically correlates with $V_{\mathrm{d}}$ and $g_{\mathrm{st}}$ over the diurnal cycle. It is thus more appropriate to compare $V_{\mathrm{d}}$ and different conductances, on which the accuracy and precision of model predictions depend in the first place in a local-scale stand-alone application of $\mathrm{DO}_{3} \mathrm{SE}$.

For the $\mathrm{DO}_{3} \mathrm{SE}$ model, both the leaf-scale parameterisation and its up-scaled version used in the EMEP model have been evaluated in various studies (e.g. Emberson et al., 2000a; 2001; Tuovinen et al., 2001; 2004; Büker et al., 2007). These evaluations have included comparisons against actual and literaturederived measurement data. As an indication of the overall performance of the $\mathrm{DO}_{3} \mathrm{SE}$ parameterisation for forests, we refer to the summary of validation studies by Emberson et al. (2007a), which shows that the correlation coefficient $(r)$ between the modelled and observation-based (half-)hourly stomatal conductance was within $0.7-0.8$ in the four studies in which $r$ was reported (three on leaf scale, one on canopy scale). In the model comparison study of Büker et al. (2007), an $r$ of 0.55 and 0.82 was obtained for the leaf-scale stomatal conductance of two forest datasets. For Mediterranean tree species, poorer agreement has been reported, indicating a need for modifications in the model selection and calibration (Elvira et al., 2007). Furthermore, when using treated plant material (Norway spruce saplings), it has been observed that the agreement can be very different between well-watered and droughtstressed plants (Karlsson et al., 2000).

The partitioning between the stomatal and non-stomatal fluxes would be essential for validating the flux models intended for risk assessment, such as $\mathrm{DO}_{3} \mathrm{SE}$. At the canopy scale, this would require data on water vapour exchange, measured with either the micrometeorological (e.g. Baldocchi et al., 2001) or xylem sap flow (e.g. Köstner et al., 1998) technique, in addition to $\mathrm{O}_{3}$ fluxes. Water vapour fluxes are observed concurrently with $\mathrm{CO}_{2}$ exchange at a large number of micrometeorological measurement sites around the world (Baldocchi et al., 2001; Reichstein et al., 2007), producing continuous long-term datasets. $\mathrm{O}_{3}$ fluxes are measured only at very few of these sites (e.g. Altimir et al., 2006), but even these data are poorly exploited in model validation. While the air quality monitoring programmes, such as that run at the ICP Forests Level II monitoring plots, can be used for testing CTMs, and can even provide an indirect evaluation on dry deposition of sulphur and nitrogen if both wet and throughfall deposition are measured (Simpson et al., 2006), they unfortunately provide little support for the validation of $\mathrm{O}_{3}$ flux models, as this (or water vapour) flux is not part of these programmes.

\subsection{Robustness analysis of $\mathrm{DO}_{3} \mathrm{SE}$ and $\mathrm{A} F_{\mathrm{st}} Y$}

Of single parameters, $g_{\max }$ is arguably the most important determinant of $F_{\text {st }}$, since this parameter defines an upper limit of $g_{\mathrm{st}}$ (Eq. (5)). Definition of $g_{\max }$ is difficult, even with the use of strict qualifying criteria (Emberson et al., 2007a), since a number of factors will influence absolute values (e.g. genotype, local climatic conditions, soil fertility). This variability is exemplified by the range in $g_{\mathrm{st}}$ values (in $\mathrm{mmol} \mathrm{O}_{3} \mathrm{~m}^{-2}$ PLA $\mathrm{s}^{-1}$ ) extracted from varying numbers $(n)$ of published literature sources used to define $g_{\max }$ for the species-specific parameterisations for Norway spruce $\left(g_{\max }=125\right.$, range $=$ $87-140, n=3)$, for central European beech $\left(g_{\max }=150\right.$, range $=132-300, n=6)$ and for holm oak $\left(g_{\max }=80\right.$, range $=134-365, n=16)($ UNECE, 2004b). Tuovinen et al. (2007) considered the consequences of data variation in relation to estimates of $F_{\mathrm{st}}$ and $\mathrm{A} F_{\mathrm{st}} Y$. Based on the standard error of the mean of the $g_{\max }$ data for deciduous forests, a corresponding uncertainty of $7 \%$ was estimated for the mean daytime $F_{\text {st }}$, while the $\mathrm{A} F_{\text {st }} 1.6$ index had an uncertainty of 14$22 \%$, depending on the location. However, the dispersion in these data was smaller than shown above. Furthermore, the possibility of systematic bias cannot be ignored since acclimation of $g_{\max }$ to local climatic conditions, such as drought, may tend to reduce gas exchange through the adoption of water conserving physiology. Unfortunately the limited number of recorded observations has so far precluded any statistical analysis of such climatic variability.

The uncertainty due to meteorological input data can be estimated by running the $\mathrm{DO}_{3} \mathrm{SE}$ model both with the in situ observed data and with the grid-averaged data obtained from a numerical weather prediction model. Tuovinen et al. (2001, 2004) concluded that the influence of the modelled input on $G_{\mathrm{st}}, R_{\mathrm{s}}$ and $V_{\mathrm{d}}$ is rather limited at two forest sites in Finland, the differences in the midsummer mean values being typically $<10 \%$. Klingberg et al. (2008) showed that the corresponding agreement for $\mathrm{A} F_{\mathrm{st}} 0$ and $\mathrm{A} F_{\mathrm{st}} 6$ (for agricultural crops in southern Sweden) is typically within 10-20\%. However, in these northern European studies no SMD effects were assumed and those of VPD were small; on a larger scale the effects are likely to be more variable. If SMD is significant, the averaging of modelled data over a grid element may become an important additional source of uncertainty, which results from underestimated intensity and overestimated frequency of precipitation at a specific location within the grid element (Emberson et al., 2007b).

The sensitivity of the $\mathrm{DO}_{3}$ SE model has also been analysed by varying some input parameters and meteorological data within prescribed "reasonable" ranges (Simpson et al., 2003b). This study showed that the parameterisation for forests exhibits varying sensitivity, but is not overly sensitive to any meteorological variable. However, the importance of the soil moisture modelling and LAI estimation is again highlighted within this analysis. A major limitation on this kind of sensitivity estimation results from the simple technique in which the input parameters are perturbed one at a time, while keeping the others unchanged. This provides only a limited view of the sensitivity. A more comprehensive estimate could be achieved by using the so-called global sensitivity analysis techniques that explore the whole parameter space (Saltelli et al., 2008).

Klingberg et al. (2008) noted the increasing sensitivity of $\mathrm{A} F_{\mathrm{st}} Y$ with increasing $Y$, which is in accordance with the previous results of Sofiev and Tuovinen (2001) and Tuovinen 
et al. (2007), who showed that this is a universal property of mathematical functions of this kind. Thus, irrespective of the stomatal flux model, the inherent sensitivity of the $\mathrm{A}_{\mathrm{st}} Y$ (as well as AOTX) index should be taken into account when setting the threshold flux for risk assessment applications. Indeed, the flux threshold for agricultural crops was reduced from $Y=6$ to $3 \mathrm{nmol} \mathrm{m}^{-2} \mathrm{~s}^{-1}$ for IAM, in order to improve the robustness of the results (UNECE, 2004b). For forest with $Y=1.6 \mathrm{nmol} \mathrm{m}^{-2} \mathrm{~s}^{-1}$, however, the situation is less severe and the overall robustness is considerably higher than for AOT40 (Tuovinen et al., 2007).

\subsection{Validation of risk estimates}

In addition to validation of the flux calculation methods, the modelled flux-based risk maps should be compared with fieldbased evidence of adverse effects. This kind of assessment has been recently carried out for crops and (semi-)natural vegetation, showing a reasonable correspondence between damage and accumulated flux (Hayes et al., 2008). For forests, monitoring activities should be developed that consider ways of assessing plant injury likely to occur from high $\mathrm{O}_{3}$ fluxes. Traditionally, attention has been placed on the use of visible injury as an indicator of adverse $\mathrm{O}_{3}$ effects. However, such injury may relate more to short episodes of very high fluxes and not be associated with biomass losses which may be more important in terms of economic or ecological damage to forest trees.

Within the ICP Forests monitoring programme, the health condition of forest trees is assessed based on observed tree crown defoliation (Lorenz et al., 2008). These data have been statistically related to different predictor variables such as $\mathrm{O}_{3}$ concentration, showing that $\mathrm{O}_{3}$-induced defoliation can be found in some parts of Europe (Klap et al., 2000; Ferretti et al., 2007). In addition to the crown condition, qualitative data on visible foliar symptoms on native vegetation have been collected at some intensive monitoring sites (Ferretti et al., 2007) and clones of an $\mathrm{O}_{3}$ sensitive poplar genotype are being tested for their suitability as bio-indicators based on visible injury (Fischer et al., 2007). Nevertheless, it would be useful to develop indicators that might be of more relevance for identifying the role that long-term $\mathrm{O}_{3}$ uptake may play in altering significant forest processes such as reduction in annual incremental biomass, plant physiology and carbon allocation (Ashmore, 2005; Matyssek et al., 2007). This would call for a connection to process-oriented research and a carefully designed monitoring strategy (Percy and Ferretti, 2004); however, such an indicator would bring the forest condition monitoring activities closer to the current flux-based critical levels, which have been developed using biomass loss as the response parameter (Karlsson et al., 2007). While it is difficult to prove dose-response relationships in the field, such information would be of great value for future policy deliberations.

\subsection{Statistical considerations}

It is important to realize that few of the validation studies discussed above can be regarded as statistically rigorous model validation, because the independence of the test data from those used for model selection and calibration has not been established. In some cases the reported statistics do not represent the prediction skill of the model at all, but rather the goodness of the calibration fit for a model modified from the original $\mathrm{DO}_{3} \mathrm{SE}$ version. The results of Karlsson et al. (2000) demonstrate how the model performance can be considerably improved by calibrating the model with local data. However, the situation is typically more ambiguous. For example, in the comparison of Scots pine data presented by Tuovinen et al. (2004), in which canopy-scale flux data were used, the good agreement reported strongly depended on the adjustment of LAI to the local value, which significantly differed from the default value set for the boreal coniferous forests in the EMEP$\mathrm{DO}_{3} \mathrm{SE}$ module.

The easiest way to obtain independent datasets is to divide each dataset randomly into two parts, one used for calibration and the other for validation (the "holdout" method). Ideally, independent data should be used for the model selection step as well, if applied. If the sample is considered too small for stratifying the data, it is possible to apply more general crossvalidation techniques in which each data point is used both for calibration and validation ("resampling" methods) (Wilks, 2006).

We recommend that more complete performance statistics should be reported than is typically the case. When applying correlation (or regression) analysis, the correlation coefficient $r$ (or the coefficient of determination $r^{2}$ ) must be considered rather meaningless alone, because the statistical significance of the agreement depends on the degrees of freedom (i.e. sample size). In addition to a quantity describing the scatter, a measure representing the model bias should be reported as a minimum. There exist a large number of statistical performance metrics that are suitable for shedding light on the different aspects of the agreement between observations and model predictions (e.g. Legates and McCabe, 1999). An illustrative way of summarising some basic metrics is the single-diagram method of Taylor (2001), which combines different metrics in a graphical form.

The original $\mathrm{DO}_{3} \mathrm{SE}$ model has five predictor functions for $g_{\text {st }}$ (Eq. (5)) that require about 30 parameters to be defined for each LCC or plant species (Emberson et al., 2000a), and there is tendency for more complicated parameterisations, for example by including $\mathrm{O}_{3}$ exposure or dose as an additional modifier (UNECE, 2004b; Pleijel et al., 2007). One may thus express concern about a danger of over-parameterisation or over-fitting (Wilks, 2006). Over-fitting occurs when the model not only fits the signal but also the noise involved in the data. In this case, a good model performance with the calibration data does not guarantee the same for independent validation data. In fact, too much complexity may result in poorer agreement with novel data (Wilks, 2006). Over-fitting may also result from the correlation between predictor variables. For example, it may be difficult to parameterise the stomatal effects of temperature and VPD, since these are typically highly correlated. The relationship between phenological and soil moisture modifiers is another source of potential redundancy. While Emberson et al. (2007a) show that the summer reduction in $g_{\text {st }}$ in the 
Mediterranean region can be explained by SMD, Alonso et al. (2008) argue that a phenological modifier improves the model performance and that there is no redundancy between these two modifiers. Nevertheless, the over-fitting and data correlation questions have not been addressed for $\mathrm{DO}_{3} \mathrm{SE}$ in a systematic manner; these issues, combined with cross validation, may deserve more attention in the future.

\section{CONCLUSIONS}

Flux-based risk assessment of $\mathrm{O}_{3}$ effects on forests is gradually superseding the exposure-based alternative, which inevitably entails the modelling of $\mathrm{O}_{3}$ deposition. This constitutes a significant additional methodological challenge. A few key issues were repeatedly highlighted in this literature-based discussion of the status of current flux calculation methods, in particular the $\mathrm{DO}_{3} \mathrm{SE}$ model. First, the modelling of soil moisture status and its effects on stomatal conductance represent a problem requiring urgent attention. Second, the data related to the physical characteristics and the seasonal dynamics of physiological activity of vegetation continue to pose problems, in spite of the promise offered by remote sensing techniques. Third, the validation of different elements associated with fluxbased risk assessment is insufficient in terms of both quantity and quality.

The uncertainties discussed in this paper cover both problems with input data (e.g. SMD) and parameter values (e.g. $\left.g_{\max }\right)$. The relative importance of the limitations associated with these varies regionally and would require a systematic sensitivity analysis. In a policy context, the major uncertainty is probably less related to the details of the $\mathrm{DO}_{3} \mathrm{SE}$ model than to knowing the correspondence between the risk maps and the actual $\mathrm{O}_{3}$-induced damage across Europe. However, we argue, firstly, that the European policy-making process is experienced in addressing such modelling-related uncertainties in risk assessments and, secondly, that the more mechanistic flux approach represents a significant improvement in the context of IAM.

As regards a European-scale monitoring strategy that could support flux-based risk assessment, there is considerable potential within the ICP Forests programme. However, it can be argued that we are dealing with a trade-off situation: on the one hand we have an inexpensive measurement method relying on passive sampling, making it possible to run an extensive network; on the other, we could replace this by introducing continuous $\mathrm{O}_{3}$ monitors. In the former case, the application of flux-based risk indicators becomes compromised by the simplifying assumptions required for the flux calculation. However, continuous monitors are too costly to be implemented across the existing ICP Forests network, even within the subset of the Level II sites.

In order to avoid the trade-off outlined above, an alternative approach could be adopted. We suggest establishing a small number of well-equipped measurement sites, "super-sites" or "Level III sites", that would provide data specifically for fluxbased risk assessment purposes. For the calculation of stomatal flux, the canopy-top $\mathrm{O}_{3}$ concentration (with vertical profiles) and all the input data needed for $\mathrm{DO}_{3} \mathrm{SE}$, including the soil water status, would be continuously measured at these sites. Similarly, the monitoring of vegetation characteristics (LAI, phenology) would be designed from the flux-modelling point of view to ensure direct usability. For further development and validation of flux models, $\mathrm{O}_{3}$ and water vapour fluxes would be measured above the canopy using the micrometeorological eddy covariance technique, possibly enhanced by sap flow and shoot-scale gas exchange measurements.

To overcome the financial and logistic restrictions, the establishment of super-sites could be accomplished in practice by collaborating with the existing flux measurement stations run across Europe, mainly within large-scale projects such as CarboEurope (Reichstein et al., 2007) and NitroEurope (Sutton et al., 2007). These constitute a potential framework for the super-sites, providing the necessary infrastructure and expertise, extensive measurement programmes and databases, as well as a direct connection to flourishing research on atmosphere-biosphere exchanges.

Acknowledgements: The work of L. Emberson was supported by the Department of Environment, Food and Rural Affairs (Defra contract AW0601PP); D. Simpson was supported by the Cooperative Programme for Monitoring and Evaluation of the Long-range Transmission of Air pollutants in Europe (EMEP) under UNECE, and by the EU NitroEurope IP (contract 017841); J.-P. Tuovinen was supported by the EU CarboEurope IP (contract 505572).

\section{REFERENCES}

Alonso R., Elvira S., Sanz M.J., Gerosa G., Emberson L.D., Bermejo V., and Gimeno B.S., 2008. Sensitivity analysis of a parameterization of the stomatal component of the $\mathrm{DO}_{3} \mathrm{SE}$ model for Quercus ilex to estimate ozone fluxes. Environ. Pollut. 155: 473-480.

Altimir N., Kolari P., Tuovinen J.-P., Vesala T., Bäck J., Suni T., Kulmala M., and Hari P., 2006. Foliage surface ozone deposition: a role for surface moisture? Biogeosciences 3: 209-228.

Amann M. and Lutz M., 2000. The revision of the air quality legislation in the European Union related to ground-level ozone. J. Hazard. Mater. 78: 41-62.

Ashmore M.R., 2005. Assessing the future global impacts of ozone vegetation. Plant Cell Environ. 28: 949-964.

Ashmore M.R., Büker P., Emberson L.D., Terry A.C., and Toet S., 2007. Modelling stomatal flux and deposition to grassland communities across Europe. Environ. Pollut. 146: 659-670.

Baldocchi D., Falge E., Gu L., Olson R., Hollinger D., Running S., Anthoni P., Bernhofer C., Davis K., Evans R., Fuentes J., Goldstein A., Katul G., Law B., Lee X., Malhi Y., Meyers T., Munger W., Oechel W., Paw U K.T., Pilegaard K., Schmid H.P., Valentini R., Verma S., Vesala T., Wilson K., and Wofsy S., 2001. FLUXNET: A new tool to study the temporal and spatial variability of ecosystemscale carbon dioxide, water vapor, and energy flux densities. Bull. Am. Meteorol. Soc. 82: 2415-2434.

Batjes N.H., 2006. ISRIC-WISE derived soil properties on a 5 by 5 arcminutes global grid (version 1.0). Report 2006/02, ISRIC - World Soil Information, Wageningen, 46 p. (URL: http://www.isric.org).

Braswell B., Schimel D., Privette J., Moore B., Emery W., Sulzman E., and Hudak A., 1996. Extracting ecological and biophysical information from AVHRR optical data: An integrated algorithm based on inverse modeling. J. Geophys. Res. 101: 23335-23348. 
Büker P., Emberson L.D., Ashmore M.R., Cambridge H.M., Jacobs C.M.J., Massman W.J., Müller J., Nikolov N., Novak K., Oksanen E., Schaub M., and de la Torre D., 2007. Comparison of different stomatal conductance algorithms for ozone flux modelling. Environ. Pollut. 146: 726-735.

Cape J.N., Hamilton R., and Heal M.R., 2009. Reactive uptake of ozone at simulated leaf surfaces: Implications for "non-stomatal" ozone flux. Atmos. Environ. 43: 1116-1123.

Chuine I., 2000. A unified model for budburst of trees. J. Theor. Biol. 207: $337-347$.

Cieslik S., 2004. Ozone uptake by various surface types: a comparison between dose and exposure. Atmos. Environ. 38: 2409-2420.

Elvira S., Alonso R., and Gimeno B.S., 2007. Simulation of stomatal conductance for Aleppo pine to estimate its ozone uptake. Environ. Pollut. 146: 617-623.

Emberson L.D., Simpson D., Tuovinen J.-P., Ashmore M.R., and Cambridge, H.M., 2000a. Towards a model of ozone deposition and stomatal uptake over Europe. EMEP/MSC-W Note 6/2000, Norwegian Meteorological Institute, Oslo, 58 p. (URL: http://www. emep.int).

Emberson L.D., Ashmore M.R., Cambridge H.M., Simpson D., and Tuovinen J.-P., 2000b. Modelling stomatal ozone flux across Europe. Environ. Pollut. 109: 403-413.

Emberson L.D., Simpson D., Tuovinen J.-P., Ashmore M.R., and Cambridge H.M., 2001. Modelling and mapping ozone deposition in Europe. Water Air Soil Pollut. 130: 577-582.

Emberson L.D., Büker P., and Ashmore M.R., 2007a. Assessing the risk caused by ground level ozone to European forest trees: A case study in pine, beech and oak across different climate regions. Environ. Pollut. 147: 454-466.

Emberson L., Morrissey T., Bueker P., Gerosa G., Finco A., and Ballarin Denti A., 2007b. Ozone flux: modelling and reliability in relation to different input data. In: Bussotti F. and Ferretti M. (Eds.), OzoneFlux - Measuring and modelling of ozone flux in evergreen Mediterranean stands of the EU Intensive Monitoring of Forest Ecosystems (Level II) - An approach at different intensity levels. Final report - Italy, Corpo Forestale dello Stato, Italia, pp. 97-132.

EMEP, 1995. EMEP manual for sampling and chemical analysis. EMEP/CCC Report 1/95, Norwegian Institute for Air Research, Kjeller, 303 p. (URL: http://www.emep.int).

EU, 2002. Directive 2002/3/EC of the European Parliament and the Council of 12 February 2002 relating to ozone in ambient air. Official Journal of the European Communities L 67: 14-30.

Ferretti M., Calderesi M., and Bussotti F., 2007. Ozone exposure, defoliation of beech (Fagus sylvatica L.) and visible foliar symptoms on native plants in selected plots of South-Western Europe. Environ. Pollut. 145: 644-651.

Fischer R., Badea O., Barbosa P., Bastrup-Birk A., Becher G., Bertini R., Calatayud V., Coenen S., de Vries W., Dobbertin M., Ferretti M., Granke O., Hiederer R., Houston-Durrant T., Köhl M., Kraft P., Lorenz M., Meyer P., Nagel H.-D., Pavlenda P., Reinds G.J., Roskams P., Sanz M., Schaub M., Schulte E., Seidling W., Solberg S., and Stofer S., 2007. The Condition of Forests in Europe, 2007 Executive Report. ICP Forests, Federal Research Centre for Forestry and Forest Products (BFH), Hamburg, 34 p. (URL: http://www. icp-forests.org).

Fuhrer J., Skärby L., and Ashmore M.R., 1997. Critical levels for ozone effects on vegetation in Europe. Environ. Pollut. 97: 91-106.

Garratt J.R., 1992. The Atmospheric Boundary Layer, Cambridge University Press, Cambridge, 316 p.
Gerosa G., Ferretti M., Bussotti F., and Rocchini D., 2007. Estimates of ozone AOT40 from passive sampling in forest sites in South-Western Europe. Environ. Pollut. 145: 629-635.

Gerosa G., Finco A., Mereu S., Vitale M., Manes F., and Ballarin Denti A., 2008. Comparison of seasonal variations of ozone exposure and fluxes in a Mediterranean Holm oak forest between the exceptionally dry 2003 and the following year. Environ. Pollut. 157: 1737-1744.

Granier A., Reichstein M., Bréda N., Janssens I.A., Falge E., Ciais P., Grünwald T., Aubinet M., Berbigier P., Bernhofer C., Buchmann N., Facini O., Grassi G., Heinesch B., Ilvesniemi H., Keronen P., Knohl A., Köstner B., Lagergren F., Lindroth A., Longdoz B., Loustau D., Mateus J., Montagnani L., Nys C., Moors E., Papale D., Peiffer M., Pilegaard K., Pita G., Pumpanen J., Rambal S., Rebmann C., Rodrigues A., Seufert G., Tenhunen J., Vesala T., and Wang Q., 2007. Evidence for soil water control on carbon and water dynamics in European forests during the extremely dry year: 2003. Agric. For. Meteorol. 143: 123-145.

Grennfelt P., Hov Ø., and Derwent D.G., 1994. Second generation abatement strategies for $\mathrm{NO}_{\mathrm{x}}, \mathrm{NH}_{3}, \mathrm{SO}_{2}$ and VOCs. Ambio 23: 425-433.

Grulke N.E., Alonso R., Nguyen T., Cascio C., and Dobrowolski W., 2004. Stomata open at night in pole-sized and mature ponderosa pine: implications for $\mathrm{O}_{3}$ exposure metrics. Tree Physiol. 24: 10011010.

Hatakka J., Aalto T., Aaltonen V., Aurela M., Hakola H., Komppula M., Laurila T., Lihavainen H., Paatero J., Salminen K., and Viisanen Y. (2003) Overview of the atmospheric research activities and results at Pallas GAW station. Boreal Environ. Res. 8: 365-383.

Hayes F., Mills G., Harmens H., and Norris D., 2008. Evidence of widespread ozone damage to vegetation. Programme Coordination Centre for the ICP Vegetation, Centre for Ecology and Hydrology, Bangor, 60 p. (URL: http://icpvegetation.ceh.ac.uk).

Jones H.G., 1992. Plants and microclimate, A quantitative approach to environmental plant physiology, Cambridge University Press, Cambridge, $452 \mathrm{p}$.

Jonson J.E., Simpson D., Fagerli H., and Solberg S., 2006. Can we explain the trends in European ozone levels? Atmos. Chem. Phys. 6: 51-66.

Juang J.-Y., Katul G.G., Siqueira M.B., Stoy P.C., and McCarthy H.R., 2008. Investigating a hierarchy of Eulerian closure models for scalar transfer inside forested canopies. Boundary-Layer Meteorol. 128: 132.

Karlsson P.E., Pleijel H., Pihl Karlsson G., Medin E.L., and Skärby L., 2000. Simulations of stomatal conductance and ozone uptake to Norway spruce saplings in open-top chambers. Environ. Pollut. 109: $443-451$.

Karlsson P.E., Braun S., Broadmeadow M., Elvira S., Emberson L., Gimeno B.S., Le Thiec D., Novak K., Oksanen E., Schaub M., Uddling J., and Wilkinson M., 2007. Risk assessments for forest trees: The performance of the ozone flux versus the AOT concepts. Environ. Pollut. 146: 608-616.

Karnosky D.F., Skelly J.M., Percy K.E., and Chappelka A.H., 2007. Perspectives regarding 50 years of research on effects of tropospheric ozone air pollution on US forests. Environ. Pollut. 147: 489-506.

Klap J.M., Oude Voshaar J.H., De Vries W., and Erisman J.W., 2000. Effects of environmental stress on forest crown condition in Europe. Part IV: Statistical analysis of relationships. Water Air Soil Pollut. 119: 387-420.

Klingberg J., Danielsson H., Simpson D., and Pleijel H., 2008. Comparison of modelled and measured ozone concentrations and meteorology for a site in south-west Sweden: Implications for ozone uptake calculations. Environ. Pollut. 155: 99-111. 
Körner C., 1994. Leaf diffusive conductances in the major vegetation types of the globe. In: Schulze E.-D. and Caldwell M.M. (Eds.), Ecophysiology of photosynthesis, Ecological Studies 100, Springer, Berlin, pp. 463-490.

Köstner B., Granier A., and Cermák J., 1998. Sap flow measurements in forest stands: methods and uncertainties. Ann. Sci. For. 55: 13-27.

Krupa S., Nosal M., Ferdinand J.A., Stevenson R.E., and Skelly J.M., 2003. A multi-variate statistical model integrating passive sampler and meteorology data to predict the frequency distributions of hourly ambient ozone $\left(\mathrm{O}_{3}\right)$ concentrations. Environ. Pollut. 124: 173-178.

Kurpius M.R. and Goldstein A.H., 2003. Gas-phase chemistry dominates $\mathrm{O}_{3}$ loss to a forest, implying a source of aerosols and hydroxyl radicals to the atmosphere. Geophys. Res. Lett. 30: 1371, DOI:10.1029/2002GL016785.

Legates D.R. and McCabe G.J., 1999. Evaluating the use of "goodness of fit" measures in hydrologic and hydroclimatic model validation. Water Resour. Res. 35: 233-241.

Loibl W., Winiwarter W., Kopsca A., Zueger J., and Baumann R., 1994. Estimating the spatial distribution of ozone concentrations in complex terrain. Atmos. Environ. 28: 2557-2566.

Lorenz M., Becher G., Mues V., and Ulrich E., 2008. Monitoring forest condition in Europe: concentrations of nitrogen and sulphur in bulk deposition and defoliation of main tree species. Int. J. Environ. Stud. 65: 299-309.

Maas R., Amann M., Apsimon H., Hordijk L., and Tuinstra W., 2004. Integrated assessment modelling - the tool. In: Sliggers J. and Kakebeeke W. (Eds.), Clearing the Air, 25 Years of the Convention on Long-range Transboundary Air Pollution, United Nations, New York, pp. 85-96.

Massman W.J., 2004. Toward an ozone standard to protect vegetation based on effective dose: a review of deposition resistances and a possible metric. Atmos. Environ. 38: 2323-2337.

Massman W.J., Musselman R.C., and Lefohn A.C., 2000. A conceptual model to develop a standard to protect vegetation. Atmos. Environ. 34: 745-759.

Matyssek R., Günthardt-Goerg M.S., Maurer S., and Keller T., 1995. Nighttime exposure to ozone reduces whole-plant production in Betula pendula. Tree Physiol. 15: 159-165.

Matyssek R., Bytnerowicz A., Karlsson P.-E., Paoletti E., Sanz M., Schaub M., and Wieser G., 2007. Promoting the $\mathrm{O}_{3}$ flux concept for European forests. Environ. Pollut. 146: 587-607.

Matyssek R., Sandermann H., Wieser G., Booker F., Cieslik S., Musselman R., and Ernst D., 2008. The challenge of making ozone risk assessment for forest trees more mechanistic. Environ. Pollut. 156: $567-582$

Meyers T.P. and Baldocchi D.D., 1988. A comparison of models for deriving dry deposition fuxes of $\mathrm{O}_{3}$ and $\mathrm{SO}_{2}$ to a forest canopy. Tellus 40B: $270-284$.

Morén A.-S. and Perttu K.L., 1994. Regional temperature and radiation indices and their adjustment to horizontal and inclined forest land. Studia Forestalia Suecica 194, Swedish University of Agricultural Sciences, Uppsala, 19 p.

Musselman R.C. and Minnick T.J., 2000. Nocturnal stomatal conductance and ambient air quality standards for ozone. Atmos. Environ. 34: 719-733.

Musselman R.C., Lefohn A.C., Massman W.J., and Heath R.L., 2006. A critical review and analysis of the use of exposure- and flux-based ozone indices for predicting vegetation effects. Atmos. Environ. 40: $1869-1888$.
Nilson T., Anniste J., Lang M., and Praks J., 1999. Determination of needle area indices of coniferous forest canopies in the NOPEX region by ground-based optical measurements and satellite images. Agric. For. Meteorol. 98-99: 449-462.

Nunn A.J., Kozovits A.R., Reiter I.M., Heerdt C., Leuchner M., Lütz C., Liu X., Löw M., Winkler J.B., Grams T.E.E., Häberle K.-H., Werner H., Fabian P., Rennenberg H., and Matyssek R., 2005. Comparison of ozone uptake and sensitivity between a phytotron study with young beech and a field experiment with adult beech (Fagus sylvatica). Environ. Pollut. 137: 494-506.

Paoletti E., De Marco A., and Racalbuto S., 2007. Why should we calculate complex indices of ozone exposure? Results from Mediterranean background sites. Environ. Monit. Assess. 128: 19-30.

Paoletti E. and Manning W.J., 2007. Towards a biologically significant and usable standard for ozone that will also protect plants. Environ. Pollut. 150: 85-95.

Percy K.E. and Ferretti M., 2004. Air pollution and forest health: toward new monitoring concepts. Environ. Pollut. 130: 113-126.

Pleijel H., Danielsson H., Emberson L., Ashmore M.R., and Mills G., 2007. Ozone risk assessment for agricultural crops in Europe: Further development of stomatal flux and flux-response relationships for European wheat and potato. Atmos. Environ. 41: 3022-3040.

Reichstein M., Papale D., Valentini R., Aubinet M., Bernhofer C., Knohl A., Laurila T., Lindroth A., Moors E., Pilegaard K., and Seufert G., 2007. Determinants of terrestrial ecosystem carbon balance inferred from European eddy covariance flux data. Geophys. Res. Lett. 34: L01402, DOI:10.1029/2006GL027880.

Saltelli A., Ratto M., Andres T., Campolongo F., Cariboni J., Gatelli D., Saisana M., and Tarantola S., 2008. Global Sensitivity Analysis: The Primer, John Wiley \& Sons, Chichester, 304 p.

Sanz M.J., Calatayud V., and Sánchez-Peña G., 2007. Measures of ozone concentrations using passive sampling in forests of South Western Europe. Environ. Pollut. 145: 620-628.

Schaub M., Emberson L., Büker P., and Kräuchi N., 2007. Preliminary results of modeled ozone uptake for Fagus sylvatica L. trees at selected EU/UN-ECE intensive monitoring plots. Environ. Pollut. 145: 636-643.

Schneider T. and Schneider J., 2004. EMEP - Backbone of the Convention. In: Sliggers J. and Kakebeeke W. (Eds.), Clearing the Air, 25 Years of the Convention on Long-range Transboundary Air Pollution, United Nations, New York, pp. 31-44.

Schöpp W., Amann M., Cofala J., Heyes C., and Klimont Z., 1999. Integrated assessment of European air pollution emission control strategies. Environ. Modell. Softw. 14: 1-9.

Schulze E.-D., Fuchs M., and Fuchs M.I., 1977. Spatial distribution of photosynthetic capacity and performance in a mountain spruce forest of northern Germany. III. The ecological significance of the evergreen habit. Oecologia 30: 239-248.

Simpson D., Tuovinen J.-P., Emberson L., and Ashmore M., 2001. Characteristics of an ozone deposition module. Water Air Soil Pollut. Focus 1: 253-262.

Simpson D., Fagerli H., Jonson J.E., Tsyro S., Wind P., and Tuovinen J.-P., 2003a. Transboundary acidification, eutrophication and ground level ozone in Europe, Part I. Unified EMEP model description, EMEP Status Report 1/2003, Norwegian Meteorological Institute, Oslo, 74 p. (URL: http://www.emep.int).

Simpson D., Tuovinen J.-P., Emberson L., and Ashmore M., 2003b. Characteristics of an ozone deposition module II: Sensitivity analysis. Water Air Soil Pollut. 143: 123-137. 
Simpson D., Fagerli H., Hellsten S., Knulst J.C., and Westling O., 2006. Comparison of modelled and monitored deposition fluxes of sulphur and nitrogen to ICP-forest sites in Europe. Biogeosciences 3: 337355.

Simpson D., Ashmore M., Emberson L., and Tuovinen J.-P., 2007. A comparison of two different approaches for mapping potential ozone damage to vegetation. A model study. Environ. Pollut. 146: 715-725.

Simpson D. and Hjellbrekke A., 2008. Photooxidants. In: Transboundary Acidification, Eutrophication and Ground Level Ozone in Europe. EMEP Status Report 1/2008, Norwegian Meteorological Institute, Oslo, pp. 43-55.

Sofiev M. and Tuovinen J.-P., 2001. Factors determining the robustness of AOT40 and other ozone exposure indices. Atmos. Environ. 35: 3521-3528.

Solberg S., Hov Ø., Søvde A., Isaksen I.S.A., Coddeville P., De Backer H., Forster C., Orsolini Y., and Uhse K., 2008. European surface ozone in the extreme summer 2003. J. Geophys. Res. 113: D07307, DOI:10.1029/2007/JD009098.

Sutton M.A., Nemitz E., Erisman J.W., Beier C., Butterbach Bahl K., Cellier P., de Vries W., Cotrufo F., Skiba U., Di Marco C., Jones S., Laville P., Soussana J.F., Loubet B., Twigg M., Famulari D., Whitehead J., Gallagher M.W., Neftel A., Flechard C.R., Herrmann B., Calance P.L., Schjoerring J.K., Daemmgen U., Horvath L., Tang Y.S., Emmett B.A., Tietema A., Peñuelas J., Kesik M., Brueggemann N., Pilegaard K., Vesala T., Campbell C.L., Olesen J.E., Dragosits U., Theobald M.R., Levy P., Mobbs D.C., Milne R., Viovy N., Vuichard N., Smith J.U., Smith P., Bergamaschi P., Fowler D., and Reis S., 2007. Challenges in quantifying biosphere-atmosphere exchange of nitrogen species. Environ. Pollut. 150: 125-139.

Tausz M., Grulke N.E., and Wieser G., 2007. Defense and avoidance of ozone under global change. Environ. Pollut. 147: 525-531.

Taylor K.E., 2001. Summarizing multiple aspects of model performance in a single diagram. J. Geophys. Res. 106: 7183-7192.

Tian Y., Dickinson R., Zhou L., Zeng X., Dai Y., Myneni R., Knyazikhin Y., Zhang X., Friedl M., Yu I., Wu W., and Shaikh M., 2004. Comparison of seasonal and spatial variations of leaf area index and fraction of absorbed photosynthetically active radiation from Moderate Resolution Imaging Spectroradiometer (MODIS) and Common Land Model. J. Geophys. Res. 109: D01103, doi:10.1029/2003JD003777.

Tuovinen J.-P., 2000. Assessing vegetation exposure to ozone: properties of the AOT40 index and modifications by deposition modelling. Environ. Pollut. 109: 361-372.

Tuovinen J.-P., Simpson D., Mikkelsen T.N., Emberson L.D., Ashmore M.R., Aurela M., Cambridge H.M., Hovmand M.F., Jensen N.O., Laurila T., Pilegaard K., and Ro-Poulsen H., 2001. Comparisons of measured and modelled ozone deposition to forests in Northern Europe. Water Air Soil Pollut. Focus 1: 263-274.

Tuovinen J.-P., Ashmore M., Emberson L., and Simpson D., 2004. Testing and improving the EMEP ozone deposition module. Atmos. Environ. 38: 2373-2385.
Tuovinen J.-P., Simpson D., Emberson L., Ashmore M., and Gerosa G., 2007. Robustness of modelled ozone exposures and doses. Environ. Pollut. 146: 578-586.

Tuovinen J.-P. and Simpson D., 2008. An aerodynamic correction for the European ozone risk assessment methodology. Atmos. Environ. 42: 8371-8381.

UNECE, 2000. Manual on methods and criteria for harmonized sampling, assessment, monitoring and analysis of the effects of air pollution on forests. Part X: Monitoring of air quality, international co-operative programme on assessment and monitoring of air pollution effects on forests, United Nations Economic Commission for Europe (UNECE) Convention on Long-range Transboundary Air Pollution, Geneva, 20 p. (URL: http://www.icp-forests.org).

UNECE, 2004a. Manual on methods and criteria for harmonized sampling, assessment, monitoring and analysis of the effects of air pollution on forests. Part VII: Meteorological measurements, international co-operative programme on assessment and monitoring of air pollution effects on forests, United Nations Economic Commission for Europe (UNECE) Convention on Long-range Transboundary Air Pollution, Geneva, 40 p. (URL: http://www.icp-forests.org).

UNECE, 2004b. Mapping critical levels for vegetation. Manual on methodologies and criteria for modelling and mapping critical loads $\&$ levels and air pollution effects, risks and trends (2008 ed.), United Nations Economic Commission for Europe (UNECE) Convention on Long-range Transboundary Air Pollution, Geneva, 254 p. (URL: http://www.icpmapping.org).

Verstraete M.M., Gobron N., Aussedat O., Robustelli M., Pinty B., Widlowski J.-L., and Taberner M., 2008. An automatic procedure to identify key vegetation phenology events using the JRC-FAPAR products. Adv. Space Res. 41: 1773-1783.

Vingarzan R., 2004. A review of surface ozone background levels and trends. Atmos. Environ. 38: 3431-3442.

Wieser G., Tegischer K., Tausz M., Häberle K.-H., Grams T.E.E., and Matyssek R., 2002. Age effects on Norway spruce (Picea abies) susceptibility to ozone uptake: a novel approach relating stress avoidance to defense. Tree Physiol. 22: 583-590.

Wilks D.S., 2006. Statistical Methods in the Atmospheric Sciences, 2nd ed., Academic Press, Amsterdam, 630 p.

WMO, 1996. Guide to Meteorological Instruments and Methods of Observation, 6th ed., WMO No. 8, World Meteorological Organization, Geneva. (URL: http://www.wmo.ch).

Zhang L., Moran M.D., and Brook J.R., 2001. A comparison of models to estimate in-canopy photosynthetically active radiation and their influence on canopy stomatal resistance. Atmos. Environ. 35: 44634470 .

Zhang X., Friedl M.A., and Schaaf C.B., 2006. Global vegetation phenology from Moderate Resolution Imaging Spectroradiometer (MODIS): Evaluation of global patterns and comparison with in situ measurements. J. Geophys. Res. 111: G04017, DOI: $10.1029 / 2006 J G 000217$. 